\title{
Editorial
}

\section{The Role of Sound in Motor Perception and Execution}

\author{
Mauro Murgia ${ }^{1,2, *}$ and Alessandra Galmonte ${ }^{3}$
}

\begin{abstract}
${ }^{I}$ Department of Pedagogy, Psychology, Philosophy, University of Cagliari, Cagliari, Italy; ${ }^{2}$ Department of Life Sciences, University of Trieste, Trieste, Italy; ${ }^{3}$ Department of Neurological, Biomedical and Movement Sciences, University of Verona, Verona, Italy
\end{abstract}

\begin{abstract}
"Perception and action" is one of the main research fields in which experimental psychologists work together with experts of other disciplines, such as medicine, physiotherapy, engineering, and sport. Traditionally, researchers have mainly focused on visual perception and on its influences on motor processes, while less attention has been dedicated to the role of auditory perception. However, in the last decade, the interest towards the influence of sounds on both action perception and motor execution has increased significantly. On the one hand, researchers have been interested in determining how humans can represent motor actions through the sounds associated with movements, as well as which auditory cues are salient for recognizing and discriminating different features of movement [1-10]. On the other hand, researchers have studied how auditory stimuli affect the production of complex movements in different domains [11-21]. The general aim of this special issue is to provide an overview of the relationship between sounds and movements by addressing theoretical, methodological, and applied issues from a multidisciplinary perspective.
\end{abstract}

\section{ORGANIZATION OF THE VOLUME}

At the beginning of this special issue we report the contributions that deal with theoretical (Steenson \& Rodger; Pizzera \& Hohmann) and methodological (Dyer, Stapleton \& Rodger) issues regarding auditory perception and action. After providing a theoretical and methodological background, we report those contributions that focus on possible applications of auditory training in the domain of sport and exercise psychology (O, Law \& Rymal; Sors, Murgia, Santoro \& Agostini), rehabilitation (Murgia, Corona, Pili, Sors, Agostini, Casula, Pau \& Guicciardi), and motor learning (Effenberg, Schmitz, Baumann, Rosenhahn \& Kroeger).

In the first article, Steenson and Rodger highlight that despite the fact that sounds are helpful in executing many dayto-day and context-specific movements and skills in everyday life, there is a surprising lack of exploration of this topic in psychological studies. In fact, the authors review the

\footnotetext{
*Address correspondence to this author at the Department of Life Sciences, University of Trieste, Via Weiss 2, 34100 Trieste, Italy; Tel. +39 0409828875; Fax: +39 0405582134; E-mail: mauromurgianet@tiscali.it
}

auditory perception literature and note that auditory perception theories mainly describe the rules governing the processing and representation of sounds in memory, and largely disregard the meaning that sounds have to individuals engaged in movement and the subsequent use of movement sounds in movement priming and execution. Steenson and Rodger's work can be framed in the context of Gibson's ecological psychology, as they emphasize the role of sound as a very important affordance that we use to interact with our environment.

In the second contribution, Pizzera and Hohmann extensively review studies that address the relevance of the mutual interactions between perception and motor control. Again, these authors highlight the scarcity of research on acoustic information, especially when comparing it with the amount of evidence available in the visual domain. Pizzera and Hohmann offer their perspective on the role of auditory information in controlling and integrating the perception and action cycle. The authors present both behavioral and neurophysiological evidence in support of the importance of auditory information in perception and action, and propose valuable suggestions that future investigators should consider in order to advance the state of knowledge in this domain.

The methodological contribution of Dyer, Stapleton and Rodger highlights the feasibility of movement sonification as an effective feedback tool for enhancing motor skill learning and performance, particularly in novices. The authors critically discuss the strengths and weaknesses of movement sonification in the context of providing efficient perceptual feedback information to learners. Dyer, Stapleton and Rodger conclude that a well-defined framework for sonification mapping has yet to be established and that there is still need for controlled trials in motor learning. However, the authors do suggest that new technologies relevant to movement sound recording, mapping, and sonification are available to researchers and can facilitate meaningful and much-needed future research on this promising perceptual feedback method.

With regards to the possible applications of audio-based interventions, the fourth article of the issue by $\mathrm{O}$, Law, and Rymal provides an overview of imagery and modeling research in sport psychology and motor learning, documenting 
evidence supporting the cognitive processing similarities between imagery and modeling. Within this background, the authors critically examine the role of the auditory sense in modeling and imagery, analyzing both theoretical issues and empirical evidence. From a bio-informational theory perspective, O, Law, and Rymal offer several examples of potential applications of the deliberate integration of the auditory sense in movement teaching and instruction, but also offer a strong caveat regarding the severe lack of applied research on the auditory sense focused on sport populations, especially in the domain of imagery. In their conclusions the authors propose detailed recommendations for future research.

A second contribution on audio-based interventions in sports is provided by Sors, Murgia, Santoro and Agostini. The authors extensively define the concepts of augmented feedback and modeling, and review studies demonstrating the effectiveness of sounds in improving the execution of simple rhythmic motor tasks. Then, Sors and colleagues describe both a theoretical background and neurophysiological evidence illustrating the mechanisms that are possibly influenced by audio-based interventions. Finally, they provide a complete description of the literature on auditory modeling and auditory augmented feedback in sports, specifying the methodological details of previous studies and proposing future directions for both, application and research.

In the sixth article, Murgia, Corona, Pili, Sors, Agostini, Casula, Pau and Guicciardi illustrate the perceptual-motor impairments of patients affected by Parkinsons' disease and new frontiers in assessment and interventions. They extensively review the empirical evidence concerning the Rhythmic Auditory Stimulation (RAS) method, describing the mechanisms underpinning its effectiveness. The authors propose possible methods for integrating auditory cues into physical therapy interventions as well as assessments. Last, Murgia and colleagues describe the biomechanical advantages of three-dimensional quantitative gait analysis, and discuss the potential impact of the incorporation of ecological footstep sounds in the modulation of patients' gait.

In the seventh and last contribution of this special issue, Effenberg, Schmitz, Baumann, Rosenhahn and Kroeger present a new method based on sonification called "SoundScript", which is aimed to facilitate the acquisition of writing. This method consists of the sonification of handwriting, that is, the conversion of physical parameters (i.e., position of the pen, pressure) into movement sounds, which provides children with auditory information which correlates with visual information of their handwriting performance. The authors report pilot data, showing that the multisensory integration elicited by SoundScript leads to a more adequate reproduction of writing kinematics. Effenberg and colleagues conclude by highlighting the potential of this new method and suggesting future steps for research.

In sum, we hope that the papers presented in this special issue constitute a useful reference for movement researchers in the field of auditory perception and action, as well as for practitioners in the domains of sport, rehabilitation, and motor learning.

\section{CONFLICT OF INTEREST}

The authors confirm that this article content has no conflict of interest.

\section{ACKNOWLEDGEMENTS}

We thank Jenny $\mathrm{O}$ for her comments on this editorial and all the reviewers for their commendable contribution to this special issue. The author Mauro Murgia was supported by Autonomous Region of Sardinia, Master and Back Programme 2013 (PRR-MAB-A2013-19330).

\section{REFERENCES}

[1] Cottrell D, Campbell MEJ. Auditory perception of a human walker. Perception 2014; 43: 1225-38.

[2] Flach R, Knoblich G, Prinz W. Recognizing one's own clapping: the role of temporal cues. Psychol Res 2004; 69(1-2): 147-56.

[3] Justen C, Herbert C, Werner K, Raab M. Self vs. other: Neural correlates underlying agent identification based on unimodal auditory information as revealed by electrotomography (sLORETA). Neuroscience 2014; 259: 25-34.

[4] Kennel C, Hohmann T, Raab M. Action perception via auditory information: Agent identification and discrimination with complex movement sounds. J Cogn Psychol 2014; 26(2): 157-65.

[5] Kennel C, Pizzera A, Hohmann T, et al. The perception of natural and modulated movement sounds. Perception 2014; 43(8): 796804.

[6] Murgia M, Hohmann T, Galmonte A, Raab M, Agostini T. Recognising one's own motor actions through sound: the role of temporal factors. Perception 2012; 41(8): 976-87.

[7] Murgia M, Santoro I, Tamburini G, et al. Ecological sounds affect breath duration more than artificial sounds. Psychol Res 2015; [epub ahead of print].

[8] Repp BH, Knoblich G. Perceiving action identity: how pianists recognize their own performances. Psychol Sci 2004; 15(9): 604-9.

[9] Santoro I, Murgia M, Tamburini G, Prpic V, Sors F, Galmonte A, Agostini T. Panic disorder patients and healthy people differently identify their own heart frequency through sound. Psihologija 2015; 48: 279-87

[10] Schmitz G, Mohammadi B, Hammer A, et al. Observation of sonified movements engages a basal ganglia frontocortical network. BMC Neurosci 2013; 14: 32.

[11] Agostini T, Righi G, Galmonte A, Bruno P. The relevance of auditory information in optimizing hammer throwers performance. In: Pascolo PB, Ed. Biomechanics and Sports. Springer: Vienna 2004; pp. 67-74.

[12] Effenberg AO. Movement sonification: effects on perception and action. IEEE Multimed 2005; 12: 53-9.

[13] Effenberg AO. Sonification: an acoustic information concept for human movement. Hofmann 1996.

[14] Karageorghis CI, Priest D-L. Music in the exercise domain: a review and synthesis (Part I). Int Rev Sport Exerc Psychol 2012; 5: 44-66.

[15] Karageorghis CI, Priest D-L. Music in the exercise domain: a review and synthesis (Part II). Int Rev Sport Exerc Psychol 2012; 5: 67-84.

[16] Kennel C, Streese L, Pizzera A, Justen C, Hohmann T, Raab M. Auditory reafferences: The influence of real-time feedback on movement control. Front Psychol 2015; 6: 69.

[17] Lahav A, Katz T, Chess R, Saltzman E. Improved motor sequence retention by motionless listening. Psychol Res 2013; 77: 310-9.

[18] Schaffert N, Mattes K, Effenberg AO. An investigation of online acoustic information for elite rowers in on-water training conditions. J Hum Sport Exerc 2011; 6: 392-405. 
[19] Thaut MH, McIntosh GC, Rice RR, Miller RA, Rathbun J, Brault JM. Rhythmic auditory stimulation in gait training for Parkinson's disease patients. Mov Disord 1996; 11(2): 193-200.

[20] Young W, Rodger M, Craig CM. Perceiving and reenacting spatiotemporal characteristics of walking sounds. J Exp Psychol Human 2013; 39(2): 464-76.
[21] Young WR, Rodger MWM, Craig CM. Auditory observation of stepping actions can cue both spatial and temporal components of gait in Parkinson's disease patients. Neuropsychologia 2014; 57: 140-53.

(C) Murgia and Galmonte; Licensee Bentham Open.

This is an open access articles licensed under the terms of the Creative Commons Attribution-Non-Commercial 4.0 International Public License (CC BY-NC 4.0) (https://creativecommons.org/licenses/by-nc/4.0/legalcode), which permits unrestricted, non-commercial use, distribution and reproduction in any medium, provided that the work is properly cited. 